\title{
ADVANCED NURSING PRACTICE: TIME AND MEANING
}

\author{
Susan Jacobs, RCpN, BScN, M.A., PhD candidate \\ Dean, Faculty of Health \& Sport Science \\ Eastern Institute of Technology, Hawke's Bay
}

\begin{abstract}
The particular, contemporary meanings ascribed to "advanced nursing practice" in New Zealand have been debated and delineated in the 1990s, culminating in the launch of the Nurse Practitioner ${ }^{\mathrm{TM}}$ at a conference sponsored by the Ministry of Health and the Nursing Council of New Zealand in August, 2001.

Drawing on archival materials, documents, other texts and voices, this article explores the evolution of connotations and meanings of the word "advanced" as applied to nursing in New Zealand. This exploration of time present, and time past, facilitates a perspective of the future.
\end{abstract}

Key Words: Advanced nursing practice, meanings over time, nursing history

\section{Introduction}

Connotations of the word "advanced" as applied to nurse, the practice of nursing and the profession of nursing have evolved over time. The particular meanings ascribed to "advanced nursing practice" in New Zealand at the turn of the 21 st century were drawn together in the late 1990s. As defined by the Nursing Council of New Zealand (NCNZ) in 2001, advanced nursing practice,

has a clinical or therapeutic focus. It is the integration of researchbased theory and expert nursing in a clinical practice area, and combines the roles of practitioner, teacher, consultant, and researcher to advance the professional practice of nursing (Canadian Nurses' Association, 1997). Advanced nursing practice reflects a range of highly developed clinical skills and judgements acquired through a combination of nursing experience and education. Essentially, advanced nursing practice requires the application of advanced nursing knowledge, with practitioners drawing not only from their clinical experience, but also on the experience and research of the profession as a whole (NCNZ, 2001, p. 28).

Drawing on the Canadian Nurses' Association's definition of advanced nursing practice, this New Zealand statement reflects movements which originated in the United States, and have spread throughout North America, Australia, and the United Kingdom.

Jacobs, S. (2003). Advanced nursing practice: Time and meaning. Nursing Praxis in New Zealand, 19(3), 29-39. 
Five key emphases feature in this definition: a focus on the clinical practitioner; an emphasis on research; the expectation that this expert clinical practitioner is also a capable teacher, consultant and researcher; the stipulation that higher level professional education is required; and the belief that this practitioner is critical to the advance of the professional practice of nursing.

Are these new elements in our understanding of advanced nursing? How does this expression of advanced nursing practice differ from historical understandings? T.S. Eliot began his 1935 poem Burnt Norton with the lines

"Time present and time past Are both perhaps present in time future,

And time future contained in time past."

$$
\text { T.S. Eliot, 1969, p. } 171
$$

Reflecting this sentiment, the present paper explores the various connotations and meanings of the concept of advanced nursing practice in New Zealand, historically and contemporarily, with a view to the future.

\section{Advanced: Further or higher education for the select few}

Higher level education is not a new element in the notion of advanced practice. Calls for nursing education to be within the university system began within the decade following statutory nursing registration. In part this was stimulated by overseas developments. For instance the New Zealand journal Kai Tiaki which began in 1910 was able to report news of a nursing degree at the University of Minnesota soon after the latter began in 1909 (Bullough \& Bullough, 1979; Hughes, 1978).

Speaking at the opening of a new nurses' home in 1912, Dr Pabst, of Auckland Hospital, urged the University of New Zealand to institute a degree in nursing (Kinross, 1984). However, in an editorial in Kai Tiaki, Hester Maclean, Assistant Inspector of Hospitals, Asylums and Charitable Institutions, founder of the New Zealand Trained Nurses' Association (NZTNA), and of Kai Tiaki, reflected the Nightingale ethos.

While we do not wish to discourage the higher teaching of nursing nor the desire to bestow honour on a profession...we must not forget that of equal importance in the training of nurses is the education of the hands as well as the brain (Maclean, 1912, cited in Miller, 1984, p. 80).

This ethos preserved the view of the male as possessor of intellect and physical strength, and the female as nurturer, possessor of traits of forbearance and obedience. "The Nightingale ethos was incompatible with advanced training for nurses" (Rodgers, 1985, p. v).

Following World War I and the influenza pandemic of 1918, many countries became more aware of the skills and contribution of nurses, and of the value of education to a developing profession. By 1922, there were seventeen degree programmes for nursing in the U.S.A., and in the UK, a diploma programme in nursing 
commenced at the University of Leeds (Bullough \& Bullough, 1979; Hughes, 1978). At this time, the NZTNA initiated a campaign to establish a programme of higher education for nurses in New Zealand. This gained the support of the Medical Superintendent of the Dunedin Hospital, Dr. Falconer, and the University of Otago. Representatives from the NZTNA and the University of Otago decided "that the best and simplest way to promote advanced education for nurses would be to institute a Diploma in Nursing which the University could approve, rather than a degree which would require the approval of the Senate of the University of New Zealand" (Hughes, p. 22).

By 1923 a five-year Diploma in Nursing had been approved in principle by the University Council. The first two years of the programme would consist of studies in chemistry, anatomy, physiology, cookery, homecraft, dietetics, sanitary science, bacteriology, and basic nursing. Years three and four would provide the hospital training, and for the fifth year, the student could study either nursing education, administration, or public health nursing.

The Department of Health, giving tacit support for the proposal, sponsored Janet Moore and Mary Lambie to study abroad for their roles as nursing lecturers. But by 1925, it was clear that the University and the Department of Health had different views on who should provide the salaries of the nursing lecturers. Perhaps more critical, neither had any commitment to the notion of higher education for nurses. In New Zealand in the 1920s, "the department provided basic training, but advanced education for nurses was a relatively new idea and one which many people thought unnecessary" (Hughes, 1978, p. 33).

The NZTNA made every effort to save the programme - even raising funds from its own members. But the programme lapsed. Janet Moore and Mary Lambie had returned to New Zealand in 1926, eager to use their education and experience. Quietly, with syllabuses of nursing programmes from the University of Toronto and Bedford College, they approached Professor Hunter at Victoria University in 1927 (Hughes, 1978). Within a year, a six-month, post-registration programme was established. Management of the programme was organised as a tripartite arrangement among Victoria University, the Wellington Hospital Board and the Department of Health, but the ultimate control of the programme rested with the latter. This was the beginning of the Postgraduate School for Nurses, later renamed the School for Advanced Nursing Studies (SANS).

The SANS Diploma in Nursing evolved to a 9-month post-registration programme, similar to that proposed for the fifth year of the University of Otago programme. Thus, further nursing education was provided for leadership positions in the fields of nursing administration, education, and public health nursing. In her memoirs, Mary Lambie comments:

When the school first began Miss Moore and I thought it would take 
us ten years to see its effect. I think it did take that time, but when I retired the school had been in operation for twenty years and by far the majority of the senior nurses in the Dominion (New Zealand) were former students. (Lambie, 1956, p.129)

This view of advanced as "senior", or a minority among the whole is echoed in Kinross' observation that "by the 1920s the pattern was set for a system of three-year apprentice-type training, followed by a one-year postgraduate education for a select few, which was to remain the predominant pattern for nursing in New Zealand for fifty years" (Kinross, 1984, p.195). From its foundation in 1928, until the first post-registration degree programmes - which specifically included nursing as a subject - were established at Victoria and Massey universities in 1973, SANS was the only educational institute offering higher education in nursing in New Zealand. Over its fifty year history, fewer than $2000 \mathrm{New}$ Zealand nurses were granted the SANS diploma (Appendix to the Journal of the House of Representatives of New Zealand, 1977).

\section{Advanced: Beyond single registration}

In 1925, when Mary Lambie went to Canada in preparation for her role as public health nursing instructor for the planned University of Otago diploma programme, she saw how the Canadian system of nursing education, while still hospital-based, was evolving to a comprehensive approach. Her perception of this was that:
Their whole system was largely different from ours in New Zealand at the time, and I felt they were talking a completely different language ...the period of training was three years and covered much of the same syllabus as in New Zealand, except there was no separate obstetrical training; each nurse was required to have three months experience in obstetrics in her general training... Further, as there was not separate training for nurses in mental hospitals, many of these hospitals had nurses from the main hospitals who were affiliated to them for a period of three months. Added to this was a new plan to give each pupil nurse some knowledge of public health nursing. Classes were held at the university and each nurse was expected to undertake two or three field visits with one of the public health nurses within a period of a month. This variety of experience made the training very comprehensive, but to my mind was superficial knowledge. (Lambie, 1956, p. 38-39)

While acknowledging the similarities between the New Zealand and Canadian systems, these comments underscore her beliefs in singlefocused (e.g. general hospital nursing, mental hospital nursing, maternity hospital nursing) learning based on service. Following a three year period of teaching at the Postgraduate School for Nurses, Mary Lambie served as the Director, Division of Nursing from 1931-1950. While comprehensive nursing programmes were being established in Canada and the USA in the 1920s, single-registration 
apprentice-style programmes persisted and proliferated in New Zealand.

Typical of her time Mary Lambie, after 11 years in practice, extended her general nurse training by undertaking the Plunket course (early infant care) in 1924, just prior to her departure for Canada. She commented on the value of "fresh interests and mental stimulus" she found in the Plunket training and believed this applied to other nurses (Lambie, 1956, p. 32). On her return from Canada she qualified in midwifery - another service oriented course - at Wellington Hospital. For many decades New Zealand nurses followed this pattern as a way of "advancing" their knowledge and skill.

\section{Advanced: Distance from direct supervision}

Views of advanced nursing practice have fluctuated with changes in societal beliefs and values, between the hospital nurse and the nurse in the community. Although "modern" nursing's origin is the hospital nurse, early trained nurses returned to nursing's roots in the home and community. Community nursing in New Zealand was established by Sibylla Maude in Christchurch in 1896, grew rapidly, and by $1909 \mathrm{St}$ John Ambulance Association and hospital boards had appointed district nurses (Burgess, 1984).

Within the hierarchical systems which prevailed in the first half of the 20th century, district and public health nurses working at a distance from the hierarchy and direct supervision of the training hospital, experienced greater freedoms and autonomy (Linebach, cited in Maggs, 1987). Peter's (2002) research on nursing in the home explores how place has the potential to restrict or enhance power and moral agency. Similarly, nurse educators and administrators also had greater freedoms, were seen as more knowledgeable, and/or having more responsibility. Drawing on Liaschencho, Peter notes, "place is important in shaping our identities and in fostering (or depleting) our sense of self and agency" (Peter, 2002, p. 25).

\section{Advanced by technical specialty}

In their research into post-basic nursing education in New Zealand, King, Fletcher and Callon (1982) noted that as far as they could ascertain, the first clinically-oriented postregistration courses commenced in 1948. That year, the Otago Hospital Board instituted a course in neurosurgical nursing, and a plastic surgery nursing course was established by the North Canterbury Hospital Board. Over the next twenty years, at least nine other courses in specialties ranging across operating theatre, cardio-thoracic, neonatal and intensive care nursing, were established by various hospital boards (King et al., 1982, p. 12).

According to King et al., (1982, p. 12) the primary reasons nurses gave for undertaking these courses included improving nursing knowledge and skills, increasing confidence and selfdevelopment, and providing an opportunity for change. As the same 
authors point out (p. 13) all these courses were extensions of the apprenticeship model, with no formal link to a tertiary educational institution, and with the students making "a significant contribution to the provision of nursing services in the units concerned".

By the 1970s nurses were increasingly defining themselves according to their specialty area of practice. Miller (1984) notes that the 1972 New Zealand Nurses' Association (NZNA) Conference approved changes to the constitution which permitted the formation of special interest sections, and by 1979, forty-four such groups had been established. This marked the beginnings of technical specialty nursing as "advanced nursing", as these nurses were often regarded by physicians, fellow nurses and the community, as possessing more complex knowledge and skills, exercising greater responsibility, and to some extent, accorded greater recognition (Albarran \& Fulbrooke, 1998).

Over time, the knowledge and skills of a specialty, may become extended to the profession at large. For example, hospital-focused general nursing education gradually came to include aspects of maternal-child health, mental health and community health, growing a broader foundation for "basic" nursing education, and thus redefining specialist knowledge. Equally, specialization legitimatised the use of knowledge and skills originally seen as the province of the physician. Coronary care nurses were taught interpretation and treatment of various arrythmias. Early intensive care and coronary care nurses developed physical assessment skills, particularly ausculation of heart and lung sounds, and abdominal assessment. Aspects of their once-specialist knowledge and skills have passed into the common curricula of preregistration education. And in a sense, these extensions advance professional practice.

\section{Advanced by experience, formal education, clinical focus and title}

In 1976, NZNA published its Policy Statement on Nursing in New Zealand: New Directions in Post-Basic Education, which proposed career alternatives for nurses, including the elaboration of several professional roles, titles and the preferred preparation for such roles. This policy statement grew from the flux of the time. The Review of Hospital and Related Services in New Zealand (New Zealand Department of Health, 1969) had identified serious problems in the health services, including the dangers inherent in the staffing of hospitals largely with students; and the inadequate preparation of nurses for the breadth and complexity of required patient care, both in and out of hospital. With the Carpenter (1971) report recommending that nursing education be established "in an appropriate educational setting" and that the "existing hospital schools be phased out" (p. 5), the organisation of nursing services, so long dependent on student nurses, was 
once again, a matter for serious concern. Then, in 1974, the wide scope of the deficiencies in pre- and post-registration nursing education, professional development and the utilisation of nurses across the health services was underlined in the fifty-nine recommendations outlined in the Board of Health's Committee on Nursing Services report, An Improved System of Nursing Services for New Zealand (New Zealand Board of Health, 1974).

Building on the recommendations, the NZNA, in the 1976 policy statement referred to above sought to accelerate the rate of transfer of pre- and post-registration nursing education to the general system of education, in technical institutes and universities. The proposal included the establishment of a preregistration nursing degree programme, and the development of clinical career structures in practice, management, and education. The document drew heavily on American nursing literature relating to the development of clinical nurse specialists, and in particular, a paper presented by Virginia Cleland (1972) at an American Nurses' Association Convention. NZNA's proposal detailed a similar hierarchy of career alternatives titled Nurse, Nurse Practitioner, Nurse Clinician, Nurse Teacher and Nurse Manager, and "a few nurses may choose to seek a position as Nurse Researcher" (NZNA, 1976, p. 17).

The Nurse was essentially the staff nurse, while the Nurse Practitioner was defined as a nurse holding a post-basic diploma or degree with an "identifiable clinical component" who functioned as a charge nurse (NZNA, 1976, p. 20). The Nurse Clinician was described (p. 22) as:

a Nurse Practitioner who has attained "a degree or graduate diploma with a clinical focus. The term nurse clinician is utilized when referring to an expanded role..., including...physical assessment, health history taking.... The setting in which the nurse (clinician) works varies between hospital and community and the time dimension of the nursing contact may extend throughout the acute and rehabilitative phase of a person's illness".

The paper gave only brief mention to the role and preparation of the Nurse Researcher.

This proliferation of titles was most likely a reaction to the incipient loss of the hospital nurse training programmes and the hierarchy of students and the relatively few staff. Judith Christensen comments on the enormous change in the role of the registered nurse working in the hospital with the transfer of nursing education from the apprenticeship system to the general education system.

The traditional reliance on employee students to provide much of nursing's work had led to a strongly hierarchical organization in which nursing was described as a list of tasks and duties... The registered nurses acted largely in a supervisory capacity. They, in turn, were supervised by the charge nurses, and they, by their 
supervisors, and so on. Now the staff nurse was to be the 'doer' of the nursing work-force with the work organized in a more holistic, patient-centred way. As the change continued throughout the seventies and early eighties, the lack of an articulated theoretical framework upon which to shape this new role became increasingly apparent. (Christensen, 1990, p. 10)

\section{Advanced Diploma in Nursing: Repeating history}

Following the establishment of the first nursing diploma programmes in polytechnics, and timed with the closure of SANS, new postregistration programmes were established in polytechnics. The first one-year Advanced Diploma in Nursing (A.D.N.) programmes commenced in 1979 in Auckland, Wellington and Christchurch, and then in Hamilton in 1980. It was argued that regionalisation of postregistration programmes would improve accessibility. This was certainly true for nurses within those regions, but as the programmes were not available through any distancemode arrangement, nurses in smaller cities and rural areas did not have significantly improved access.

A focus of the A.D.N. programmes was for "increased emphasis on their clinical content - the aim being to prepare advanced practitioners" (Burgess, 1984, p. 76). With this direction, the A.D.N.s provided "a common core module of advanced nursing studies" (Bazley, 1978, p. 25) for example nursing theory, social and biological sciences, not unlike the Postgraduate School for Nurses / School for Advanced Nursing Studies (SANS). The remainder of the year focused on a clinical area: community health, medical-surgical, maternal and child health, midwifery or psychiatric nursing. However unlike SANS, the A.D.N.s did not offer programmes to prepare nurse educators or nurse administrators.

In a sense, these programmes were an anachronistic compromise. With nursing education transferred to technical institutes, and postregistration degree programmes established within Massey and Victoria universities, it would have been more in keeping with the recommendations of the Carpenter report to have developed distancebased, undergraduate degree programmes designed to prepare nurses in clinical specialties, health system management and nursing education. However, a conservative view persisted within nursing. Indeed, as Nan Kinross noted as early as 1984 ,

it is true that the present system of a three year basic nursing programme, followed by a one-, two- or three-year post-basic programme seems a long and arduous road to the two qualifications required to be a nurse, and to advance to the next professional step on the ladder. (1984, p. 199)

\section{Expanded, specialised and advanced: A contemporary view}

The contemporary concept of advanced nursing practice is defined 
in many ways across the nursing literature. One point of agreement appears to be the focus on clinical practice. The American Association of Colleges of Nursing (AACN) refer to the advanced practice nurse as "any nurse prepared at the master's degree level to provide direct client care" (AACN, 1996, p.12).

The International Council of Nurses (ICN) and the ICN Nurse Practitioner/ Advanced Practice Nursing Network provide the following definition:

\section{A Nurse Practitioner/Advanced Practice Nurse (NP/APN) is a registered nurse who has acquired the expert knowledge base, complex decision-making skills and clinical competencies for expanded practice, the characteristics of which are shaped by the context and/or country in which $\mathrm{s} / \mathrm{he}$ is credentialed to practice. A masters level degree is recommended for entry level (ICN, n.d.).}

Characteristics of the NP/APN, as delineated by the ICN relate to the nature of the educational preparation, nursing practice, and regulatory mechanisms. The practice of the NP/ APN is expected to integrate research, education and management; to involve advanced health assessment and diagnostic reasoning skills; and to include the right to diagnose, prescribe, refer and admit patients to hospital. Finally; the title for advanced practice will be officially recognised.

Implicit in the ICN definition and characteristics are three components: specialisation, expansion, and advancement. The American Nurses' Association (ANA), in its 1995 Social Policy Statement, describe these components:

Specialisation is concentrating or delimiting one's focus to part of the whole field of nursing. Expansion refers to the acquisition of new practice knowledge and skills, including knowledge and skills that legitimize role autonomy within areas of practice that overlap traditional boundaries of medical practice. Advancement involves both specialization and expansion and is characterized by the integration of a broad range of theoretical, research-based, and practical knowledge that occurs as part of graduate education in nursing. (Hamric, 1996, p. 46)

Nurse Practitioner ${ }^{\mathrm{TM}}$, is the title given to a particular "innovative role for registered nurses working at an advanced level" (Ministry of Health, 2002, p. 1). Launched in August 2001 at a conference sponsored jointly by the Ministry of Health and the Nursing Council of New Zealand, the criteria and competencies for endorsement as a New Zealand Nurse Practitioner ${ }^{\mathrm{TM}}$ with prescribing rights are commensurate with the ICN definition and characteristics.

\section{Then and now}

An examination of New Zealand archival material and nursing literature of the last century reveals advanced nursing referring to a diverse range of circumstances. 
These connotations of 'advanced' have included:

1. Nurses with higher education;

2. Nurses with more than one type of registration;

3. Nursing outside the hospital walls, or with less direct supervision, especially community health, nursing education, and nursing administration;

4. Specialty nursing, especially a technical specialty;

5. A higher position within a hierarchy of nursing titles; and most recently

6. An expert, masters-prepared clinical practitioner with expanded and specialist knowledge and skills.

The conceptualisation of advanced nursing as the clinical practitioner, rather than more broadly applied to include nurse educators and nurse administrators and some others, is a shift in emphasis, which re-emerged in New Zealand in the 1990s.

\section{Conclusion}

This exploration of the evolution of meanings of advanced nursing recalls nursing's history: its Nightingale legacy, its hierarchical structures, its difficulties in the socio-political sphere, the social construction of nurse/woman, and the profession's struggle to gain control over its own education and practice. Belich (2001) offers caution on the "dangers of presentism": of portraying an earlier era as a dark past "to which the present is a solution" (p. 545-546). On the other hand, he notes "the main problem with the history of the present is simply that we don't know what happens next” (Belich, p. 392).

At the turn of the 21 st century thinking about advanced nursing is focused on a view of the clinical practitioner who, through master's degree preparation develops advanced practice characterised by the integration of an expanded range of practical, theoretical and evidencebased therapeutics to patient care. The prospect of continuing evolution leads to the question, will the advanced practice nurse of tomorrow hold a professional doctorate?

\section{References}

Albarran, J., \& Fulbrooke, P. (1998) Advanced nursing practice: An historical perspective. In G. Rolfe \& P. Fulbrooke (Eds.), Advanced nursing practice (pp.11-32) Oxford: Butterworth Heinemann.

American Association of Colleges of Nursing. (1996). The essentials of master's education for advanced practice nursing. Washington, DC: Author.

Appendix to the Journal of the House of Representatives of New Zealand. (1977). The public health: Report of the Department of Health for the year ended 1977. H-31.

Bazley, M. (1978). Post-basic nursing education in technical institutes. New Zealand Nursing Journal, 71(8), 25.

Belich, J. (2001). Paradise reforged: A history of the New Zealanders. Auckland: Allen Lane: The Penguin Press 
